\title{
A Study of Constructing Ecological English Education
}

\author{
Sun Lei \\ Xi'an International University \\ China, 710077 \\ 553107794@qq.com
}

\begin{abstract}
Ecology of education is the study of the education from the perspective of ecology. The teaching of ecology seems to present difficulties for most biology and other school teachers. This paper analyzes some main reasons teachers face in teaching ecology. At the end of the study, the author tried to detect the corresponding suggestions to improve the ecologic classroom basing on the related ecologic theories.
\end{abstract}

Keywords-Ecology, English Classroom, Constructing Ecology, Biology Education

\section{INTRODUCTION}

With the social development, the concept of ecology is widely used in people's life. At the same time, the relationship between the environment and human beings is placed in a more important place. The view of coordinated development between environment and people can be put in the field of education. Within the field of environment studies is the subdiscipline of environmental education that is rooted in the belief that education has a role to play in helping to improve human treatment of the natural environment. Hungerford, Peyton, Wilke argue that the ultimate goal for Environmental education should be: "to provide an education which results in environmentally-affirmative citizenship”. Specifically, however, the most commonly found goals of environmental education are: (a) to develop ecological knowledge and awareness; (b) to develop problem-solving and scientific inquiry skills (such as observation and identification, investigation and classification, clarification and interpretation, and reasoning and evaluation); and (c) to develop the motivation, abilities and dedication to act in ecologically and socially desirable ways, individually as well as collectively. In other words, the goals of environmental education are to develop environmentally literate citizens and to ensure that they become "a necessary prerequisite for effective participation in today's society."

Nowadays many teachers pay more attention to promote the students' scores in schools. That is the commonly phenomenon in China. In the long term for sustainable educational development, it is really needed to be changed. For it is not good to shape all round development of students. When teaching English, students' learning initiative may not be fully activated in the scores-oriented English learning and teaching. In the meantime, students and English teachers are not in the equal position in the English education. That is to say, teachers are in the main position and give instruction to the students. While the students are in the subordinate position, they follow instructions passively. It damages the students' English learning interest greatly.

\section{THE GOALS OF BIOLOGY EDUCATION}

Hurd, Bybee, Kahle, and Yager proposed the following basic instructional statements for biology education:

(1). Biology education should develop a fundamental understanding of biological systems.

(2). Biology education should develop a fundamental understanding of, and ability to use the methods of scientific investigation.

(3). Biology education should contribute to an understanding and fulfilment of personal needs and thus contribute to the development of individuals.

(4). Biology education should inform students about careers in the biological sciences.

These basic statements of instruction reflect the five goals of biology education which are: biological knowledge, scientific methods, social issues, personal needs, and career preparation.

Furthermore, the Science Council of Canada lists four main aims, which further translate into several goals in the British Columbia secondary school biology curriculum[1]. These goals are:

Goal A-Biology curriculum should provide opportunities for students to develop scientific attitudes, and to develop positive attitudes toward science.

Goal B-Biology curriculum should provide opportunities for students to acquire the skills and understand the processes of science.

Goal C-Biology curriculum should provide opportunities for students to increase their understanding of the basic concepts and principles of biological science.

Goal D-Biology curriculum should provide opportunities for students to develop critical and abstract thinking abilities.

If all the above mentioned goals for biology education are adequately implemented, they will be relevant not only to science teachers and science or biology students, but to the vast majority of future citizens, regardless of their ultimate careers, 
because they also reflect the calls for a new emphasis on biosocial and ecological goals in biology education.

\section{THE INSTRUCTION OF ECOLOGY EDUCATION}

Expository techniques (such as lecture, advance organizer, operant conditioning models of teaching, etc., which reflect a highly structured environment) are still the popular teaching approaches among many biology teachers at the secondary school level. Teaching has not changed much over the years. Even the influence of the 1950's which saw a strong call for change in science teaching to focus on scientific inquiry, problem-solving discussion and group investigation methods, and reasoning ability had little effect1 Teachers lecture more than $75 \%$ of the time, follow the traditional expository sequence consisting of the assignment, the test, discussion of the test and later retest to see whether the information is still in storage[2]. These teaching models reflect a highly structured environment and clearly emphasize the teacher's own choices in making instructional decisions.

Extensive use of expository teaching explains the findings of many researchers that students spend at least $70-95 \%$ of their time in classrooms working with text materials and that most science teachers use textbooks as the primary instructional resource in the classroom. Field work, laboratory activities, scientific inquiry, and problem-solving and discussion methods which imply a significant amount of student decision-making and the application of biological knowledge to environmental problems, are not used in the classroom. Therefore, as Hill concludes, biology teaching "...has not yet taken a sufficient account of either the practice of science or of the modem philosophical analysis of science and so has not yet succeeded in reflecting biological reality”.

\section{The Difficulties Teachers Face in Teaching ECOlOgY}

Numerous educators have agreed that the teaching of ecology presents a difficult task at any level, especially in the field. Teaching ecology has been seen to pose more special problems, both intellectual and administrative than any other area of biology. As a result, ecology topics are poorly represented in teaching syllabuses and examination schemes. In this section an examination of the literature with respect to the difficulties of teaching ecology will be made, beginning with the 1979 study by Booth. Some reasons emerge from the literature for the difficulties teachers face in teaching ecology.

\section{A. Confusion in Teaching Ecology}

Booth summarizes five issues causing teachers difficulty in teaching ecology. These include:

(1).The isolation of ecology as a separate topic within a biology or science course rather than treating it as an integral part of the course.

(2).A tendency to treat ecological work as "project" work lacking the more precise end-points of other experimental work

(3).A tendency to look for new discoveries in ecology rather than working towards end-points which are within definite limits of which at least the teacher is aware.
(4).The use of techniques (e.g. use of quadrants, transacts) without defining what questions are being asked, often for the sake of the technique only.

(5).Attempts to take on complicated tasks in which the number of variables involved makes progress almost impossible (the large number of variables which have to be considered in most ecological investigations is one of the major difficulties encountered in studying the subject.).

\section{B. Lack of Experience in Evaluating Students Performance in Ecology}

Booth and Moss and Theobald found that students answering ecology questions obtained lower marks than those who answered other questions in biology examinations, even when ecology was a specified part of the curriculum[3]. There is considerable controversy among teachers on how to introduce ecological questions to students and how to examine their knowledge and understanding of ecology. Some teachers feel that some form of coursework or internal assessment is essential. There is some relationship between this view and some of the traditional views of ecology teaching. Examination questions may have encouraged the teaching of "theoretical ecology" with little or no firsthand experience. Internal assessment would ensure that data were obtained firsthand.

\section{Lack of Teacher Confidence in Dealing with Ecological Issues}

Many teachers lack confidence, especially regarding the identification of organisms in ecology teaching. It is inevitable that teachers who have never been trained to develop identification skills or to use them in teaching will be at a disadvantage. Teachers are aware of this, and they see familiarity with many living organisms of a given area as an important factor in understanding the environment and in teaching ecology. Teachers with little or no ecology background, in either content or method, will likely kill any interest students may have in the study of ecology, not only in high school, but also in college.

\section{Lack of Appropriate Facilities}

The field has been recognized by many educators as one of the main facilities in conducting effective ecology teaching, especially when valid information about local educational sites and their organisms, easy organization of students, free time in the school timetable, adequate funding, and small class size are available. Ludwing, who believes that "whole ecosystems cannot be maintained in the classroom", suggests that the best way to teach the holistic component of the environmental system is in the ecosystem itself, in the field or at the zoo or museum[4]. He sees ecology as field oriented work where students can, "perceive the complementary relationship of pattern and organized process-with the processes of the whole". He adds that "while the difficulty and complexity of field trip participation and learning must be considered, field trips are vital for holistic understanding of systems too large to be studied in the classroom”. 


\section{E. Lack of Emphasis in Developing Observing Skills}

In studying biology, observation is the key to stimulating the minds of pupils to think about a particular object(s) or relationship(s) in a given ecosystem. Most of all, observation is essential in the development of concrete thinking. It is the basis for the pupil's development of formal or abstract thought. "Understanding biology increasingly depends upon the development of abstract, or formal thinking”, because formal thinking is necessary in the formulation and testing of hypotheses. It seems ironic that scientific observation is viewed as neither suitable as a subject of education nor even useful as a guide to science instruction. This is true despite the fact that, "one legitimate goal of science teaching is to promote accurate views of nature and the role of scientific investigation”.

Two views emerged in the study of observation skills in the literature. One view is that teachers are required to teach observation only indirectly because of a shortage of time. So, rather than let their students look for something to observe and make their own legitimate inferences, they (teachers) tell them what to observe and what their observations will mean. They ask their students, for example, to determine the characteristics of things, to see the changes in growing things, to learn the habits of animals, and to see the results of experiments, etc. In observation such as this, there is no room for biased, overly subjective observation or rational disagreement between students and/or the teacher.

The other view is that observation is related to complex mental processes, and can only be accomplished through structured observation activity. According to Norris scientific observation requires "the operation of complex and elaborate mental processes". Thus it should be represented at least at the senior levels of schooling as a complex activity "requiring considerable planning, the construction and coordination of complicated apparatus, and much thought in conceiving in the first place what observations to expect”.

\section{IMPLICATIONS}

Some effective solutions can be used according to the class observation procedure and the ecologic theories and principles, such as obeying the law of tolerance and the most moderate principle to improve the students' development, using the edge effect and coordinate evolution law to input activities to classrooms.

\section{CONCLUSION}

Ecology of education is the study of the education from the perspective of ecology. It's a long way to get the balanced ecological education. It needs not only the teachers, students and colleges, but also the cooperation of the whole society. Being the English educational educator, English teachers have to shape and form the concepts and renew the teaching methods as well. In addition, the society has to supervise the development of ecology education.

\section{REFERENCES}

[1] Edwards, A. D., and Westgate, D. P. Investigating Classroom Talk. LonDon: The FalmerPress, 1994. Print.

[2] Lawrence, A. C Public Education. Michigan: Basic Books, 1976. Print.

[3] Leather, J., and J.VanDam. Ecology of Language Acquisition. Dordrecht: Kulwen Academic Publishers, 2003. Print.

[4] Widdowson, H. G TeachingLanguage as Communication. Oxford: Oxford University Press, 1978. Print. 